\title{
The Effect of DDAVP Infusion on Thrombin Generation in Platelet-rich Plasma of von Willebrand Type 1 and in Mild Haemophilia A Patients
}

\author{
Irene M. L. W. Keularts, K. Hamulyak, H.C. Hemker, Suzette Béguin \\ From the Department of Biochemistry, Cardiovascular Research Institute Maastricht (CARIM) \\ and Medical Faculty University of Maastricht, The Netherlands, Academic Hospital Maastricht,
} The Netherlands

\section{Key words}

Thrombin generation, von Willebrand factor, factor VIII, DDAVP

\section{Summary}

In von Willebrand disease (vWD) type 1 and mild haemophilia A patients we studied the effect of an infusion of DDAVP $(0.3 \mu \mathrm{g} / \mathrm{kg}$ body weight) on thrombin generation in platelet-rich plasma (PRP) and platelet-poor plasma (PPP). Baseline thrombin generation in PRP was diminished both in the haemophilia $\mathrm{A}$ and $\mathrm{vWD}$ patients. It was normal in vWD plasma when sufficient procoagulant phospholipids were present, either via adding phospholipid vesicles to PPP or via scrambling of the platelet membrane with ionomycin in PRP. In haemophilia A plasma, thrombin generation did not normalize by providing procoagulant phospholipids. Treatment with DDAVP temporarily restored thrombin generation in PRP to normal in both diseases.

To investigate the individual roles of von Willebrand factor (vWF) and factor VIII, we also studied the effect of factor VIII infusion on thrombin generation in a severe haemophilia patient. It appears that at a fixed normal vWF concentration, $<25 \%$ factor VIII is sufficient for normal thrombin generation in PRP. At a sufficient factor VIII concentration, however, thrombin generation is still lower than normal in vWD patients; $40 \%$ of vWF is required for half-normal thrombin generation in PRP.

It thus appears that vWF is also a clotting factor, in the sense that it is required for normal thrombin generation. This underlines the importance of the interaction between coagulation and the platelets in normal haemostasis. Thrombin generation in PRP appears to be a suitable test to reflect the combined function.

\section{Introduction}

Two functions of von Willebrand factor (vWF) have been established; it serves as an adhesive ligand via which platelets can aggregate and adhere to subendothelial matrix components or fibrin, especially at high shear rate and it also is the carrier/stabilizer of factor VIII (FVIII) (1-4).

Correspondence to: Dr. S. Béguin, Synapse bv. CARIM, University Maastricht, P.O. Box 616, 6200 MD Maastricht, The Netherlands Tel. +31 43 3881672; Fax: 3143 3884159; E-mail. s.beguin@thrombin.com
Recently, a third function of vWF has been described: its role in the development of platelet procoagulant activity. Neutralization of vWF diminishes thrombin generation in PRP by $\sim 60-70 \%$ whereas intrinsic thrombin generation in PPP remains normal, indicating that the effect cannot be ascribed to a disturbance of the function of factor VIII (5). A defect in thrombin generation in PRP, and therefore presumably in whole blood in vivo, might contribute to the bleeding problems of von Willebrand (vWD) type 1 patients. Treatment of vWD patients with the vasopressin analogue DDAVP causes a release of vWF and factor VIII from endothelial cells and a temporary rise in their plasma levels (6). Such rises can be effective in reducing the bleeding risk (7).

We studied the effect of DDAVP infusion on thrombin generation in plasma of vWD type 1 patients and in a mild haemophilia A patient. DDAVP normalized thrombin generation in PRP in both cases but only in haemophilia A, there was an effect on thrombin generation in PPP.

\section{Patients, Material and Methods}

Chemicals

Apyrase and bovine serum albumin (BSA) were purchased from Sigma (St Louis, MO, USA). The chromogenic substrate used for thrombin determination was S2238 (H-D-Phe-Pip-Arg-pNA.2HC1). Staphylocoagulase was prepared as described earlier (8). The phospholipid vesicles used consist of 20 mole- $\%$ phosphatidyl serine (PS) and 80 mole-\% phosphatidyl choline (PC) and were prepared as previously described (9). Bovine purified factors $\mathrm{Va}, \mathrm{Xa}$ and human prothrombin were kindly provided by dr. R Wagenvoord (Synapse bv., University Maastricht, The Netherlands). Kaolin ("Kaolin léger") was provided by B.L.B. Laboratoires du Bois de Boulogne (Puteaux-France). Ionomycin was purchased from Sigma (St Louis, MO, USA). Recombinant FVIII (rFVIII) (Kogenate, Bayer, Switzerland) is reported to contain no detectable vWF activity (10).

\section{Buffers/Solutions}

Buffer A consists of $20 \mathrm{mM}$ hepes, $150 \mathrm{mM} \mathrm{NaCl}, 0.5 \mathrm{~g} / \mathrm{l}$ bovine serum albumin (BSA), pH 7.35. Buffer B is buffer A with $20 \mathrm{mM}$ EDTA added at $\mathrm{pH} 7.9$.

\section{Blood and Plasma}

Blood was obtained through an antecubal venapuncture from apparently healthy individuals and patients who consented to participate in this study. Platelet-rich plasma (PRP) was prepared by centrifugation of freshly drawn blood (1 volume tri-sodium citrate $0.13 \mathrm{M}$ to 9 volumes blood) at $265 \mathrm{~g}, 10 \mathrm{~min}$ at $25^{\circ} \mathrm{C}$. The platelets were counted and PRP was adjusted to $300 \times 10^{9} / \mathrm{L}$ with 
Table 1 Baseline data on the vWD and haemophilia patients

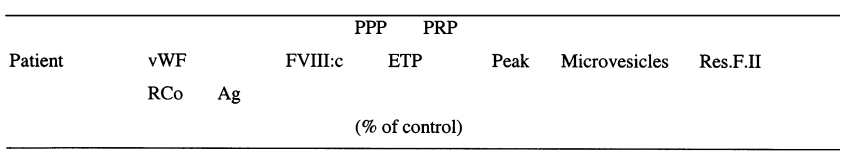

\begin{tabular}{lllllllll}
\hline vWD type 1 & & & & & & & & \\
A & 17 & 21 & 50 & 93.6 & 15 & 29 & 29 & 26 \\
B & 49 & 52 & 72 & 98 & 57 & 53 & 50 & 14 \\
& & & & & & & & \\
Haem A (mild) & & & & & & & & 51 \\
C & 51 & 59 & 8 & 87 & 5.7 & 12.9 & 31 & 8 \\
D & 75 & nd & 31 & 99 & 98 & 84 & 67.5 & 89 \\
Haem A (severe) & & & & & & & & \\
E & 101 & nd & $<1$ & 10.2 & 0 & 0 & 25.8 & \\
\end{tabular}

autologous PPP. Platelet-poor plasma (PPP) was made by double centrifugation at $2900 \mathrm{~g}, 10 \mathrm{~min}$ at $25^{\circ} \mathrm{C}$.

Patients

After informed consent and as a part of the normal treatment schedule, a test dose of DDAVP was given to 3 patients in which the effect of such treatment was to be assessed, i.e. to two von Willebrand disease type 1 (patients A and B) and two mild haemophilia A patients (C) (8\% FVIII:c). One severe haemophilia A patient with factor VIII <1\% (patient E) received a factor VIII infusion ( $25 \mathrm{IU} / \mathrm{kg}$ body weight). In addition, baseline thrombin generation was studied in another haemophilia A patient with 31\% FVIII:c (patient D). The baseline data on these patients are given in Table 1. The diagnosis of patient $\mathrm{B}$ was also based on the fact that at previous occasions she had shown vWF levels in the range of 25 and $40 \%$ of normal.

\section{vWf and Factor VIII Determination}

vWF antigen (vWF: Ag) was determined with the Sta Liatest vWF kit from (Boehringer Stago, Mannheim, Germany) according to Newman et al. (11). $\mathrm{vWF}$ ristocetin cofactor activity $(\mathrm{vWF}: \mathrm{RCoF})$ was determined according to standard procedures (12). Factor VIII activity (FVIII:c) was determined with the IL Test ${ }^{\mathrm{TM}}$ APTT-SP kit from Instrumentation Laboratory (Lexington, MA,
USA). Normal plasma from 60 healthy males and non-pill using females was pooled and used as a reference.

\section{Thrombin Generation Test in PRP}

PRP (480 $\mu \mathrm{l})$ was incubated with $120 \mu \mathrm{l}$ buffer $\mathrm{A}$ at $37^{\circ} \mathrm{C}$ and the mixture was gently stirred with a Teflon coated magnet. After 5 min, coagulation was initiated with $120 \mu \mathrm{l}$ of $100 \mathrm{mM} \mathrm{CaCl}_{2}$. At $30 \mathrm{~s}$ or $1 \mathrm{~min}$ intervals after triggering, $10 \mu \mathrm{l}$ was removed from the reaction mixture and introduced into prewarmed cuvettes containing $490 \mu \mathrm{l}$ of buffer B with $200 \mu \mathrm{M}$ S2238 in order to measure thrombin. The clot formed in the reaction mixture was left in the serum without disrupting proper sampling or the sampling rhythm. After about $2 \mathrm{~min}$, the reaction in the cuvettes containing the subsamples was stopped with $300 \mu \mathrm{l}$ of $1 \mathrm{M}$ citric acid. A computer recorded sampling and stopping times. Optical densities were measured with a spectrophotometer at $405 \mathrm{~nm}$. From the $\mathrm{OD}$, the recorded reaction time and the calibration factor $(1 \mathrm{OD} / \mathrm{min}=725 \mathrm{nM}$ thrombin), the amidolytic activity in the samples was calculated. The timecourse of thrombin was obtained from the amidolytic activity data as described earlier (13). Residual sera were kept on ice and centrifuged at high speed for $1 \mathrm{~min}$ to remove remaining cells and debris; then they were stored at $-80^{\circ} \mathrm{C}$ for later analysis of procoagulant microparticles and residual prothrombin.

\section{Intrinsic Thrombin Generation in PPP}

In plastic tubes, under continuous agitation at $37^{\circ} \mathrm{C}, 240 \mu \mathrm{l}$ of PPP was incubated with $40 \mu \mathrm{l}$ of buffer A in which $0.25 \mathrm{mg} / \mathrm{ml}$ kaolin was suspended. After 4 min, $20 \mu \mathrm{l}$ of $100 \mu \mathrm{M}$ phospholipid vesicles (20/80 mole-\% PS/PC) (final concentration: $1.11 \mu \mathrm{M}$ ) was added. Thrombin generation was triggered

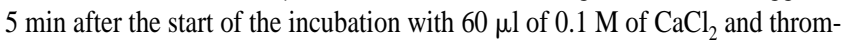
bin generation was measured according to the above-described procedure.

\section{Calculation of Free Thrombin}

From the thrombin generation curve in PRP, the amount of free thrombin was calculated from the amidolytic activity curves as described before (14) and expressed as the area under the thrombin generation curve (the ETP - endogenous thrombin potential). If the end level of amidolytic activity was not reached within 30 minutes, the pseudo first order decay constant of the $\alpha_{2}$ macroglobulin-thrombin formation could not be calculated according to the standard procedure (13) and was determined independently from the thrombin generation curve in extrinsically triggered, non defibrinated platelet-poor-plasma.
Fig. 1 Thrombogram in the two vWD patients and a mild haemophilia A patient. Upper panel left: Normal PRP (adjusted to 50\% FVIII activity with haemophilia A plasma [101\% vWF:RCoF]), $\square$ PRP patient A, PRP patient $\mathrm{B}, \bigcirc \mathrm{PRP}$ patient $\mathrm{A}$, pretreated with $10 \mu \mathrm{M}$ ionomycin. Insert upper panel (right): $\mathbf{\Delta}$ normal PPP, $\triangle$ PPP of patient A. Lower panel: $\mathbf{D}$ Normal PRP, $\square$ PRP patient $\mathrm{C}, \boldsymbol{P}$ PRP patient $\mathrm{D}, \boldsymbol{\Delta}$ normal PPP, $\triangle \mathrm{PPP}$ of patient $\mathrm{C}$
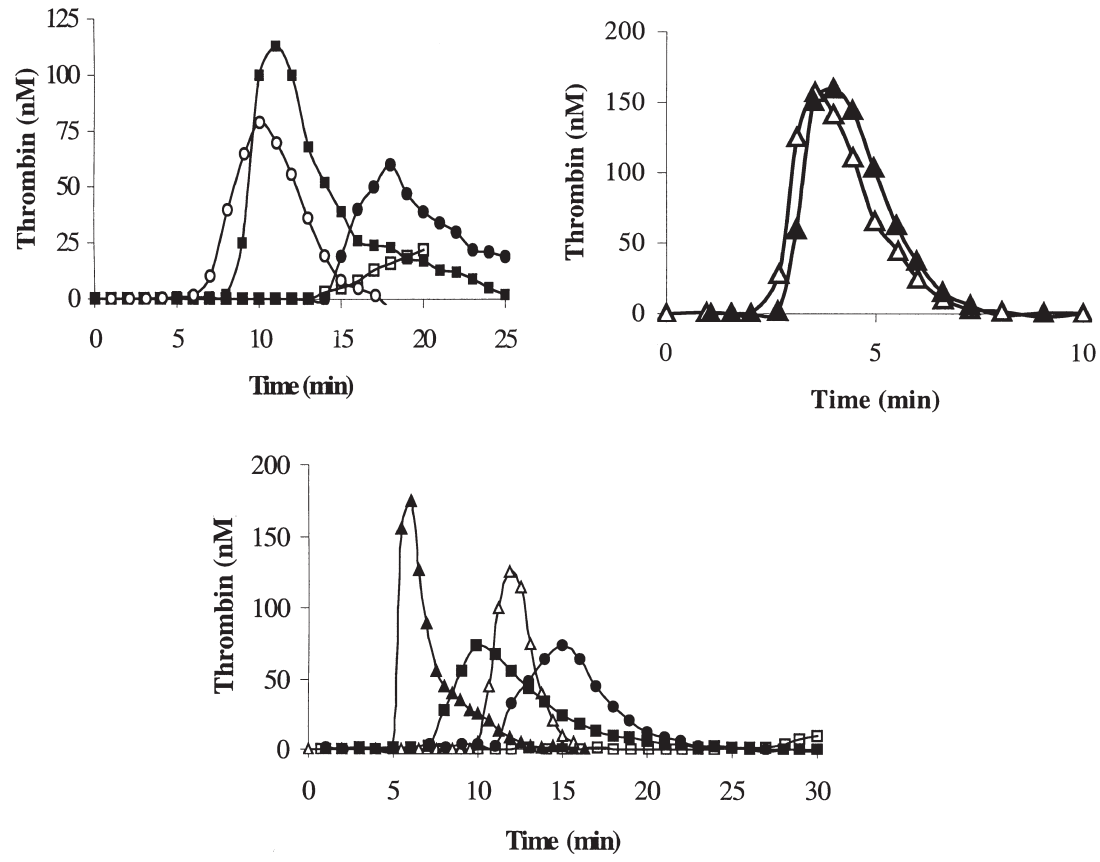

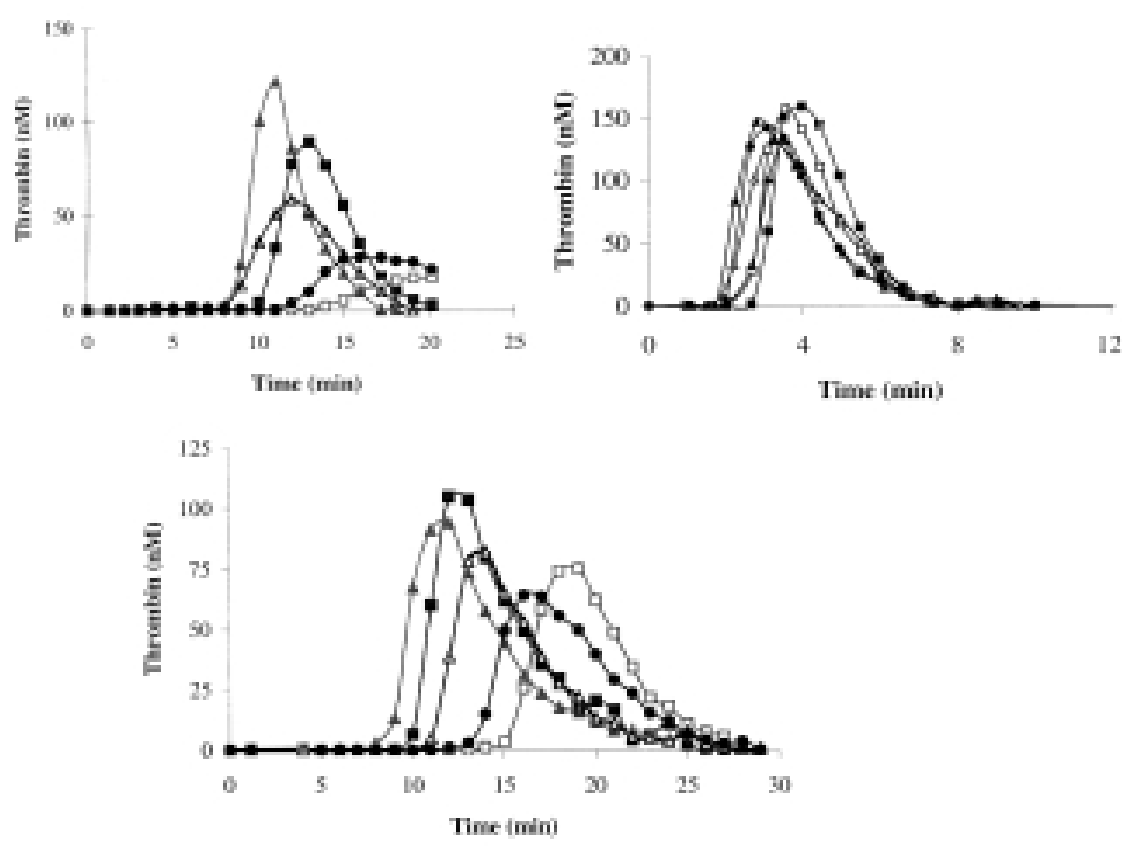

Fig. 2 Effect of DDAVP on the thrombin generation in PRP of the vWD patients A (upper panels) and B (lower panel). $\square$ Normal donor, $\square$ vWD patient before treatment, $\boldsymbol{\Delta} 2$ hrs (patient A: 60\% vWF:RCo, 188\% FVIII:c and patient B: $170 \%$ vWF:RCo, 282\% FVIII:c), $\triangle 6$ hrs (patient A: $40 \%$ vWF:RCo, 120\% FVIII: $c$ and patient B: 107\% vWF: RCo, 137\% FVIII:c), 24 hrs (patient A: 25\% vWF:RCo, 62\% FVIII:c and patient B: 50\% vWF:RCo, 51\% FVIII:c) after treatment. Insert upper panel right: thrombin generation in PPP of patient A

\section{Measurement of Platelet Derived Procoagulant Phospholipids in Serum}

Sera were diluted 3:17 in buffer A. $50 \mu$ l of diluted serum was incubated with $50 \mu$ l of a $6 \mu \mathrm{M}$ prothrombin solution in buffer A. After 5 min of incubation at $37^{\circ} \mathrm{C}, 50 \mu \mathrm{l}$ of a solution consisting of $24 \mathrm{mM} \mathrm{CaCl}_{2}, 21 \mathrm{nM} \mathrm{FVa}$ and $0.87 \mathrm{nM}$ FXa in buffer A was added. After 4 min of incubation, $10 \mu \mathrm{l}$ of this mixture was added to a cuvette containing $465 \mu$ l of buffer B. After the addition of $25 \mu \mathrm{l}$ of S2238 (final concentration of $200 \mu \mathrm{M}$ ), dA/dt at $405 \mathrm{~nm}$ was determined, from which thrombin concentrations were calculated.

\section{Measurement of Residual Prothrombin in Serum}

Staphylocoagulase complexes with prothrombin in a stoichiometric staphylocoagulase-prothrombin complex, which has the same specific activity towards small molecular weight (chromogenic) substrates as thrombin $(8,15)$. The sample (10 $\mu$ l of either PPP diluted 1:20-1:100 or serum diluted 1:4 in hepes buffer A) was incubated with $465 \mu \mathrm{l}$ buffer B containing staphylocoagulase $(0.22 \mu \mathrm{M})$.

After $10 \mathrm{~min}$ incubation, $25 \mu \mathrm{l}$ of $4 \mathrm{mM}$ S2238 was added and the amidolytic activity measured. For the serum, the spontaneous activity due to $\alpha_{2} \mathrm{M}$ thrombin is subtracted from the activity obtained in the presence of staphylocoagulase. The amount of prothrombin consumed is expressed as a $\%$ of the plasma prothrombin concentration.

\section{Results}

The baseline characteristics of the two von Willebrand deficient (vWD) patients (A, B) are given in Table 1 and Fig.1. In accordance with earlier observations (5), it is seen that thrombin generation in PRP is impaired only as long as it is dependent upon the exposure of procoagulant phospholipids by the platelet. Thrombin generation in vWD patients was normal in PPP (intrinsic pathway, i.e. contact activation in the presence of phospholipids) and in PRP after scrambling the membrane with ionomycin (Fig. 1, upper panel). In a mild haemophilia patient $(\mathrm{C})$, however, thrombin generation was impaired both in PRP and PPP triggered via the intrinsic pathway. In the other haemophilia A patient (patient D) with $31 \%$ factor VIII, thrombin generation was normal except for the prolonged lag-phase in PRP (Fig.1).

To all three patients, an intravenous infusion of DDAVP was given $(0,3 \mu \mathrm{g} / \mathrm{kg}$ body weight $)$ and the effect on thrombin generation was measured before and 2, 6 and $24 \mathrm{hrs}$ after (Figs. 2, 3).
In all cases, thrombin generation in PRP transiently normalized. In the vWD patients, no effect was seen on thrombin generation in PPP (intrinsic pathway, Fig. 2 insert) or in PRP to which ionomycin was added (results not shown). In the mild haemophilia patient (patient $\mathrm{C}$ ), however, diminished thrombin generation in PRP mirrored similar effects in PPP. Not only peak heights and area under the curve were influenced by DDAVP infusion but also the lag phase of thrombin
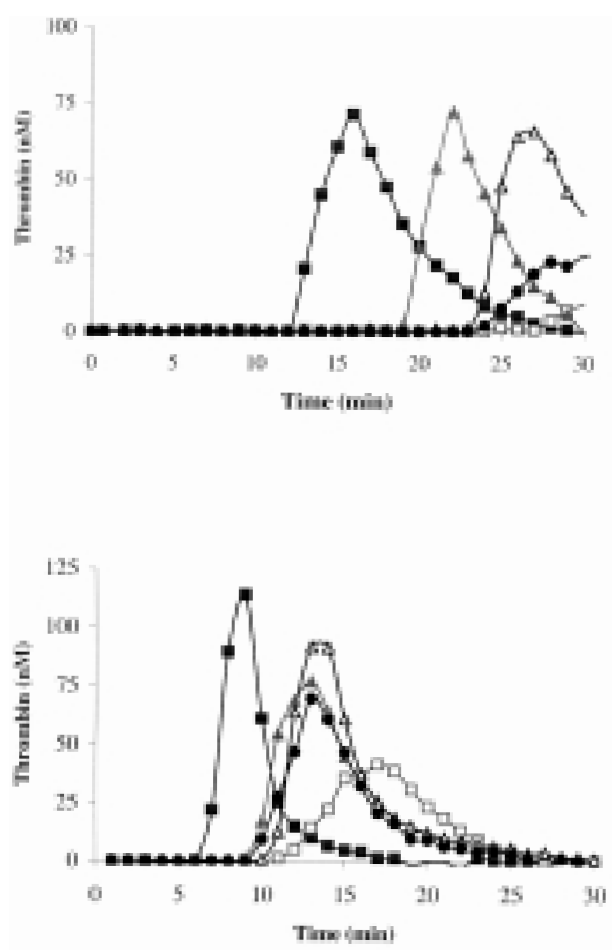

Fig. 3 Effect of DDAVP on thrombin generation in PRP of a mild haemophilia patient $\mathrm{C}$. Thrombin generation is shown in PRP (upper panel) and PRP pretreated with $10 \mathrm{mM}$ ionomycin (lower panel). Control (84\% vWF: Ag; 81\% vWF:RCo; $58 \%$ factor VIII:c), $\square$ patient $\mathrm{C}$ before treatment, $\boldsymbol{\Delta}$ patient $\mathrm{C}$ at 2 hrs $(206 ; 105 ; 30), \triangle 6$ hrs $(140 ; 132 ; 23), \bigcirc 24$ hrs $(104 ; 78 ; 10)$ after DDAVP infusion 

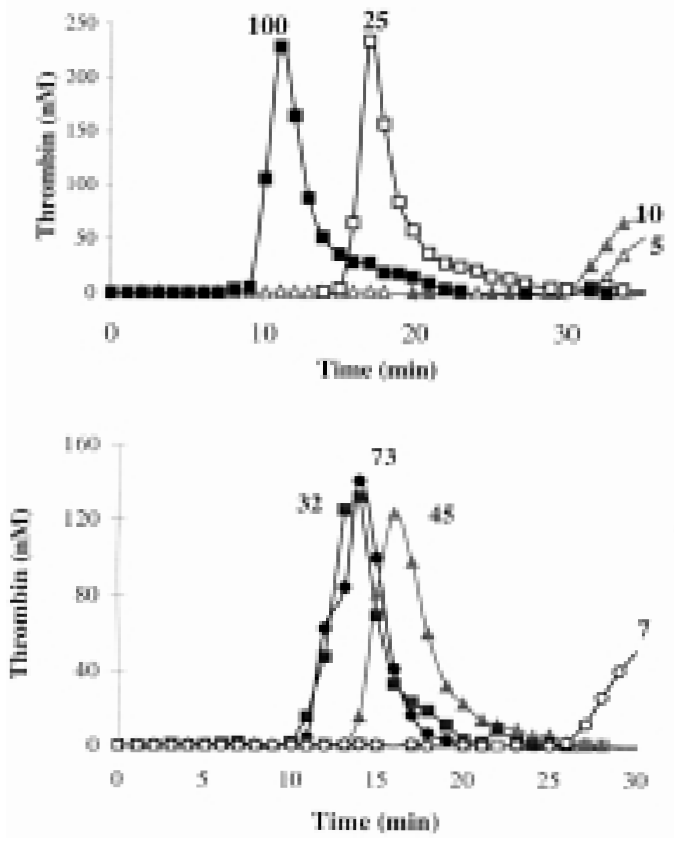

Fig. 4 The effect of factor VIII on thrombin generation in PRP of a severe haemophilia A patient (E). Upper panel: Patient $\mathrm{E}$ (factor VIII <1\%) received a bolus of $250 \mathrm{IU}$ rFVIII and the thrombogram in PRP was measured $0.5 \mathrm{hrs}(\boldsymbol{\Delta}$; 45\% FVIII), $3 \mathrm{hrs}(\boldsymbol{\square} ; 32 \%)$ and $24 \mathrm{hrs}(\bigcirc ; 7 \%$ FVIII) after treatment. No thrombin generation was observed before administration of factor VIII. Lower panel: $\mathrm{PRP}$ of a the same patient obtained at $\mathrm{t}=0$, was spiked with $1 \%$ (same as baseline, no response), $5 \%(\triangle), 10 \%(\mathbf{\Delta}), 25 \%(\square)$ and $100 \%(\mathbf{\square})$ of recombinant factor VIII

formation tended to shorten. Lag phase changes were more pronounced in the haemophilia patient than in vWD patients (Figs. 2, 3).

These observations raise the question of the relative dependency of thrombin generation in PRP on factor VIII and von Willebrand factor (vWF). In order to study the effect of variation of factor VIII at a fixed vWF content, we investigated the effect of factor VIII in a severe haemophilia A patient (E) with a normal vWF level. Factor VIII levels were changed either by infusion (in vivo) or by in vitro spiking the plasma with recombinant factor VIII (Fig. 4).

The dependency of the area under the curve of the thrombogram (ETP) on the factor VIII concentration is shown in Fig. 5. If vWF is not rate limiting, only a low concentration of factor VIII $(<20-25 \%)$ is required for normal function. vWD patients consistently show low thrombin generation at factor VIII levels that are themselves sufficient to ensure normal thrombin generation in haemophiliacs, i.e. in the presence of normal concentrations of vWF (Fig. 5). In our vWD patients, factor VIII therefore is not rate limiting in thrombin generation. In Fig. 6, we show the dependency of thrombin generation on vWF. It is seen that half-maximal thrombin generation is observed at $\sim 40 \% \mathrm{vWF}$.

\section{Discussion}

Von Willebrand factor deficiency (vWD) brings about a defect in platelet function that not only shows as impaired adhesion and aggregation but also as diminished thrombin generation in platelet-rich plasma (16). We previously have shown that vWF binds to fibrin and then interacts with platelet receptor GPIb (5). This is one of the activation routes that brings about a reorganisation of the platelet membrane in which procoagulant phospholipids, usually confined to the inside of the cell membrane, appear at the outside. They thus come into contact with the plasma milieu and can serve as a support to the prothrombin- and factor X converting enzyme complexes (17). The low factor VIII levels in von Willebrand disease are not instrumental in this low thrombin generation, as can be concluded from the fact that thrombin generation practically normalises in $\mathrm{vWD}$ as soon as sufficient procoagulant phospholipids are provided $(5,16)$. The baseline data of the patients presented here (Fig.1, Table 1) confirm these observations. In PRP, thrombin formation is abnormal in both vWD patients and haemophiliacs. Scrambling the platelet membrane with ionomycin normalises thrombin generation in vWD PRP but not in PRP of haemophilia A patients. The same difference between the two diseases is seen in PPP, triggered via contact activation and provided with phospholipids.

In Figs. 2 and 3, it is seen that administration of DDAVP normalises thrombin generation in both diseases. DDAVP, by chasing factor VIII and $\mathrm{VWF}$ from their endothelial reservoirs, brings about a transient rise in these two factors (see ref. 18 for a recent review). In haemophilia A plasma, the normalisation of the thrombogram must be attributed to the rise in factor VIII, because normal levels of vWF are already present at baseline. The dependency of thrombin generation on factor VIII is further illustrated by the observations in a severe haemophiliac (Fig. 4). When the level of the deficient factor is augmented, either by spiking the deficient PRP in vitro or by intravenous injection to the patient of a factor VIII preparation (free of vWF), thrombin generation increases.

The dose response curve of factor VIII and the ETP is shown in Fig. 5. It shows: (a) no obvious differences between PRP and PPP (b) normalisation of the ETP by low $(<25 \%)$ concentrations of factor VIII as soon as sufficient $\mathrm{vWF}$ is present and (c) a clear difference between the response in $\mathrm{vWD}$ and in haemophilia $\mathrm{A}$. This reinforces the conclusion that diminished thrombin generation observed in $\mathrm{vWD}$ is unrelated to the lack of factor VIII but must be attributed to the low level of vWF.

It is common knowledge that the normal levels of clotting factors in plasma are largely sufficient to ensure normal function of the clotting

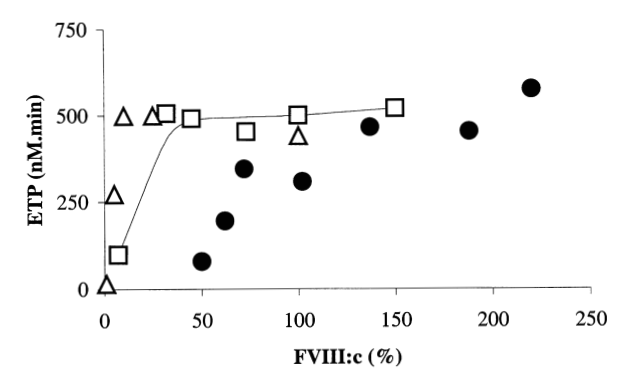

Fig. 5 Activity-effect relationship of factor VIII and the ETP, vWD PRP, $\square$ Haem A PRP, $\triangle$ Haem A PPP

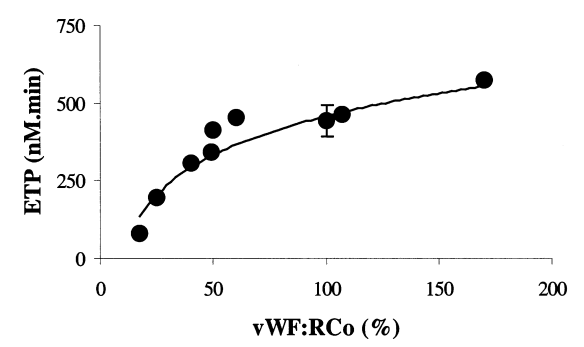

Fig. 6 Concentration-effect relation of vWF and the ETP in vWD patients 
system. Severe clinical problems are usually seen only at levels $<5 \%$ and are rare at levels $>12-20 \%$ (19). In the case of the vitamin K-dependent factors, it is well known that oral anticoagulant treatment at a level of $20-40 \%$ of normal is associated with a very mild increase of bleeding complications in a large population $(20,21)$.

Our data show that, as long as vWF is not rate limiting, the ETP becomes near to maximal at factor VIII concentrations of $>20 \%$. This suggests a correlation between the ETP and clinical bleeding. Levels of $5-10 \%$ factor VIII were originally reported to cause relieve in bleeding episodes in haemophilia A (22), at this level we do see some thrombin generation (Fig. 4). In modern therapy with factor VIII concentrates levels, of $\sim 20-30 \%$ are commonly accepted to be sufficient (23) and at this level thrombin generation can hardly be distinguished from normal. The normal level thus represents a functional excess of factor VIII and variations around and above this level will not cause significant variations in thrombin generation.

In contrast to factor VIII and other clotting factors, normal levels of vWF seem not to represent a significant excess. Half-maximum thrombin generation is observed at $\sim 40 \%$ of the normal level (Fig. 6). This suggests that variations around the $100 \%$ level will reflect in thrombin generation. Epidemiological observations on the relation between vWF and thrombosis show that a rise of vWF above the normal level is accompanied by an increased risk of thrombosis and presumably therefore by a more active mechanism of thrombin generation in PRP (24).

We think that the present data demonstrate that thrombin generation is a promising function test for that part of the haemostatic mechanism that is contained in PRP, vWF included. In view of the heterogeneity of vWD $(25,26)$, further observations on the PRP of patients with vWD will have to show what the precise relationship is between thrombin generation and bleeding tendency in different types of this disease.

\section{Acknowledgement}

The authors thank the technical staff of Haematology, Haemostasis unit (academic hospital Maastricht, The Netherlands) for determination of vWF:RCoF, vWF:Ag and FVIII:c in plasmas. This study was supported by a Program Grant 900-26-192 from the Dutch Organization for Scientific Research (N.W.O.).

\section{References}

1. Ruggeri ZM, Ware J. von Willebrand factor. Faseb J 1993; 7 (2): 308-16. 2. Sadler JE. von Willebrand factor. J Biol Chem 1991; 266 (34): 22777-80.

3. Meyer D, Girma JP. von Willebrand factor: structure and function. Thromb Haemost 1993; 70 (1): 99-104.

4. Sixma JJ, Bolhuis PA, Sakariassen KS. Thrombogenesis: interaction of blood components with the vessel wall. Recent Results Cancer Res 1979; 69: 111-8.

5. Béguin S, Kumar R, Keularts I, Seligsohn U, Coller BS, Hemker HC. Fibrin-dependent platelet procoagulant activity requires GPIb receptors and von Willebrand factor. Blood 1999; 93 (2): 564-70.

6. Lethagen S. Desmopressin - a haemostatic drug: state-of-the-art review. Eur J Anaesthesiol Suppl 1997; 14: 1-9.
7. Federici AB, Mannucci PM. Optimizing therapy with factor VIII/von Willebrand factor concentrates in von Willebrand disease. Haemophilia 1998; 4 (Suppl 3): 7-10.

8. Hendrix H, Lindhout T, Mertens K, Engels W, Hemker HC. Activation of human prothrombin by stoichiometric levels of staphylocoagulase. J Biol Chem 1983; 258 (6): 3637-44.

9. Rosing J, Tans G, Govers-Riemslag JW, Zwaal RF, Hemker HC. The role of phospholipids and factor $\mathrm{Va}$ in the prothrombinase complex. J Biol Chem 1980; 255 (1): 274-83.

10. Boedeker BG. The manufacturing of the recombinant factor VIII, Kogenate. Transfus Med Rev 1992; 6 (4): 256-60.

11. Newman DJ, Henneberry H, Price CP. Particle enhanced light scattering immunoassay. Ann Clin Biochem 1992; 29 (Pt 1): 22-42.

12. Allain JP, Cooper HA, Wagner RH, Brinkhous KM. Platelets fixed with paraformaldehyde: a new reagent for assay of von Willebrand factor and platelet aggregating factor. J Lab Clin Med 1975; 85 (2): 318-28.

13. Hemker HC, Willems GM, Béguin S. A computer assisted method to obtain the prothrombin activation velocity in whole plasma independent of thrombin decay processes. Thromb Haemost 1986; 56 (1): 9-17.

14. Hemker HC, Béguin $S$. Thrombin generation in plasma: its assessment via the endogenous thrombin potential. Thromb Haemost 1995; 74 (1): 134-8.

15. Kawabata S, Morita T, Iwanaga S, Igarashi H. Staphylocoagulase-binding region in human prothrombin. J Biochem (Tokyo) 1985; 97 (1): 325-31.

16. Béguin S, Kumar R. Thrombin, fibrin and platelets: a resonance loop in which von Willebrand factor is a necessary link. Thromb Haemost 1997; 78 (1): 590-4.

17. Bevers EM, Comfurius P, Zwaal RF. The nature of the binding for prothrombinase at the platelet surface as revealed by lipolytic enzymes. Eur J Bioch 1982; 122 (1): 81-5.

18. Aledort LM. Some aspects on the management of hemophilia. Thromb Haemost 1995; 74 (1): 440-3.

19. Roberts HR, Graham JB, Webster WP, Penick GD. Plasma transfusion therapy in hemophilia. In: The hemophilias. Brinkhous KM, Hemker HC, eds. Chapel Hill: University of North Carolina Press 1964; 323-7.

20. Loeliger EA. Therapeutic target values in oral anticoagulation-justification of Dutch policy and a warning against the so-called moderate-intensity regimens. Ann Hematol 1992; 64 (2): 60-5.

21. Azar AJ, Cannegieter SC, Deckers JW, Briet E, van Bergen PF, Jonker JJ, et al. Optimal intensity of oral anticoagulant therapy after myocardial infarction. J Am Coll Cardiol 1996; 27 (6): 1349-55.

22. Biggs R, Macfarlane RG. Haemophilia and related conditions: a survey of 187 cases. Br J Haematol 1958; 4: 1-27

23. Mannucci PM. Haemophilia treatment protocols around the world: towards a consensus. Haemophilia 1998; 4 (4): 421.

24. Catto AJ, Carter AM, Barrett JH, Bamford J, Rice PJ, Grant PJ. von Willebrand factor and factor VIII: $\mathrm{C}$ in acute cerebrovascular disease. Relationship to stroke subtype and mortality. Thromb Haemost 1997; 77 (6): 1104-8.

25. Sadler JE, Matsushita T, Dong Z, Tuley EA, Westfield LA. Molecular mechanism and classification of von Willebrand disease. Thromb Haemost 1995; 74 (1): 161-6.

26. Sadler JE. A revised classification of von Willebrand disease. For the Subcommittee on von Willebrand Factor of the Scientific and Standardization Committee of the International Society on Thrombosis and Haemostasis. Thromb Haemost 1994; 71 (4): 520-5.

Received February 22, 2000 Accepted after resubmission May 17, 2000 